\title{
Involvement of TRPA1 receptors in meningeal blood flow induced by formation of nitroxyl (NO-/HNO)
}

\author{
M Dux ${ }^{1 *}$, M Eberhardt $^{2}$, MR Filipovic ${ }^{3}$, R DeCol $^{2}$, K Messlinger $^{2}$ \\ From The European Headache and Migraine Trust International Congress \\ London, UK. 20-23 September 2012
}

\section{Introduction}

Activation of TRPA1 receptors has recently been shown to cause release of calcitonin gene-related peptide (CGRP) from trigeminal ganglion neurons and to increase meningeal blood flow in animals (Kunkler et al. 2011 ,), events regarded to be associated with headaches. Meningeal blood flow is also increased by donors of nitric oxide (NO), partly mediated by the release of CGRP from meningeal afferents (Strecker et al. 2002).

\section{Objective}

The release of CGRP provoked by NO donors may be indirectly induced by the formation of nitroxyl (NO-/ HNO), a reduced congener of NO (Switzer et al. 2009), which may activate TRPA1 receptors of meningeal afferents. Considering this possibility we examined the role of $\mathrm{NO}-/ \mathrm{HNO}$ in a rat model of meningeal blood flow.

\section{Methods}

In isofluorane anaesthetised rats, meningeal blood flow was recorded by laser Doppler flowmetry. Sodium-alphaoxyhyponitrite (Angeli's salt, AS, $300 \mu \mathrm{M}$ ), which mainly produces NO-/HNO, was topically applied to the cranial dura mater. The distribution of TRPA1 immunoreactive neurons in the trigeminal ganglion was determined by indirect immunohistochemistry.

\section{Results}

Application of AS caused increases in meningeal blood flow lasting several minutes. Topical pre-administration of $50 \mu \mathrm{M} \mathrm{HC}-030031$, a specific inhibitor of TRPA1 receptors, reduced the blood flow increases to the half.
Topical applications did not change arterial blood pressure and heart rate. TRPA1 receptor immunoreactivity was found in a proportion of small trigeminal ganglion neurons.

\section{Conclusions}

We conclude that NO-/HNO can increase meningeal blood flow by activating TRPA1 receptors, most likely through stimulation of CGRP release from meningeal afferents. Similar mechanisms may be involved in the pathophysiology of headaches associated with the endogenous NO metabolism.

\section{Author details}

${ }^{1}$ Department of Physiology, University of Szeged, Hungary. ${ }^{2}$ Institute of Physiology \& Pathophysiology, University of Erlangen-Nuernberg, Germany. ${ }^{3}$ Department of Chemistry and Pharmacy, University of Erlangen-Nuernberg, UK.

Published: 21 February 2013

References

1. Kunkler PE, Ballard CJ, Oxford GS, Hurley JH: TRPA1 receptors mediate environmental irritant-induced meningeal vasodilatation. Pain 2011 152:38-44.

2. Strecker T, Dux M, Messlinger K: Nitric oxide releases calcitonin generelated peptide from rat dura mater encephali promoting increases in meningeal blood flow. J Vasc Res 2002, 39:489-496.

3. Switzer $\mathrm{CH}$, Flores-Santana W, Mancardi D, Donzelli S, et al: The emergence of nitroxyl (HNO) as a pharmacological agent. Biochim Biophys Acta 2009, 1787:835-840.

doi:10.1186/1129-2377-14-S1-P88

Cite this article as: Dux et al:: Involvement of TRPA1 receptors in meningeal blood flow induced by formation of nitroxyl (NO-/HNO). The Journal of Headache and Pain 2013 14(Suppl 1):P88. 